\title{
LOS AMBIGUOS JUEGOS DEL ACASO EN PEOR ESTÁ QUE ESTABA Y MEJOR ESTÁ QUE ESTABA ${ }^{1}$
}

\author{
Simon Kroll \\ Erwin Schrödinger-Stipendiat \\ Ruprecht-Karls-Universität Heidelberg \\ Romanisches Seminar \\ Seminarstraße 3 \\ 69117 Heidelberg \\ Alemania \\ simon.kroll@gmail.com
}

\section{1. ¿SOMOS TODOS FULLEROS? ¿QUÉ ES UN AZAR?}

Quisiera empezar esta contribución sobre el artificio cómico de Calderón con unas reflexiones acerca de los tahúres y fulleros. En pinturas de la época la casa de juegos era un tema frecuente. Piénsese en los Jugadores de cartas de Michelangelo Caravaggio (h. 1595) ${ }^{2}$, Los juga-

1 Este artículo forma parte del proyecto «Secrets and Secrecy in Calderón's Comedy and in Spanish Golden Age Culture», financiado por el Austrian Science Fund (P24903-G23) y el Anniversary Fund del Österreichische Nationalbank (14725). Le agradezco su ayuda durante la preparación de este texto a Wolfram Aichinger, Robert Folger, Fernando Rodríguez-Gallego y Andrea Toman-Kroll.

${ }^{2}$ Michelangelo Caravaggio, Jugadores de cartas o Partida de cartas, 134 x $97 \mathrm{~cm}$, óleo sobre lienzo, Fort Worth, Kimbell Art Museum. 
dores de cartas, de Gerrit van Honthorst, (h. 1620) o $^{3}$ las dos pinturas de Georges de la Tour con el tramposo del as (h. 1620; h. 1630) ${ }^{4}$.

Miremos como ejemplo el cuadro de Caravaggio. Aparecen tres personas de las cuales dos están jugando a las cartas, mientras que la tercera parece estar mirando las cartas de uno de ellos, dando señales al otro jugador situado en el lado derecho del cuadro. Este joven tiene unas cartas escondidas con las que supuestamente puede ganarse una ventaja, luego es de suponer que él es el fullero. Tiene además un mirón quien le informa sobre las cartas que tiene su adversario. En este cuadro parece fácil identificar a los tramposos y al jugador engañado. En las imitaciones del tema en Honthorst y La Tour, por ejemplo, ya no resulta tan fácil definir quién es el fullero, puesto que representan un ambiente en el que todos parecen tratar de engañar a todos ${ }^{5}$. En ambos pintores aparece un grupo más grande de jugadores y toda una serie de distintas estrategias, como mirones, cartas falsas o trucos con la luz para ganarse ilícitamente una ventaja sobre el otro.

El fullero es la figura que trata no solo de calcular el azar, sino de controlarlo, antiguo reto de la física. Hasta el siglo xx la física no admitía acontecimientos sin causas, es decir, azares. En el imaginario de Newton o Laplace, por ejemplo, cada movimiento tenía que ser explicable, Newton aboga en algunos momentos a Dios, mientras que Laplace ya no necesitaba dicha figura ${ }^{6}$. La fisica del siglo $x x$ pone en tela de juicio estas teorías. El azar, aquello que no tiene una causa definida, como ya lo había descrito Aristóteles mucho antes, vuelve a existir en las teorías de la mecánica cuántica. En ellas encontramos la diferenciación entre los azares epistémicos y los azares objetivos ${ }^{7}$. Los epistémicos son los que nosotros experimentamos cada día, al barajar las cartas o al jugar

${ }^{3}$ Gerrit van Honthorst, Los jugadores de cartas, h. 1620, 125 x 190 cm, Óleo sobre lienzo, Museum Wiesbaden, Inventarnr. M 409.

${ }^{4}$ Georges de la Tour, Tramposo del as de diamantes, h. 1630,106 x $146 \mathrm{~cm}$, Óleo sobre lienzo, Paris, Musée du Louvre (Thuillier, 2003, p. 248). Los datos de la segunda y casi idéntica obra del tema son: Georges de la Tour, Tramposo del as de tréboles, h. 1620, $96 \mathrm{x}$ $156 \mathrm{~cm}$, Fort Worth, Kimbell Art Museum (Thuillier, 2003, p. 246). El tema fue presente en las obras de más artistas de la época, como, por ejemplo, en la de Gerrit Dou, Nicolas Régnier, Wouter Pietersz Crabeth II, Bartolomo Manfredi o en la de Valentin de Boulogne y se merecería un coloquio interdisciplinario.

${ }^{5}$ Brême, 1997, p. 76.

${ }^{6}$ Zeilinger, 2007, p. 20.

${ }^{7}$ Martínez Muñoz, 1991. 
a los dados. ¿Por qué cae esta carta precisa en primer lugar?; ¿por qué aquella cara del dado? El fullero lo sabe y a pesar de que se trate de un tramposo, nos demuestra que este azar no es del todo azaroso, valga la contradicción. Conociendo todas las variables involucradas, la densidad del aire, el peso del dado, el viento que sopla o no sopla, la fuerza con el que y el ángulo desde el que cae el dado (y probablemente algunas variables más), sería posible calcular cómo caerá el dado.

No obstante, existe otro tipo de azar que hoy por hoy no somos capaces de calcular de ninguna manera. Se trata de ciertos acontecimientos que describe la física cuántica como, por ejemplo, la descomposición de un neutrón. Sabemos que se va a descomponer en un lapso de tiempo determinado, pero no somos capaces de calcular el momento exacto de su descomposición ${ }^{8}$. Este tipo de azares se han llamado objetivos en curiosa coincidencia con las teorías del hazard objective del surrealista Bretón.

\section{Algunos aspectos del artificio cómico de Calderón}

Calderón tenía que enfrentarse a problemas parecidos a los de los directores y guionistas de Hollywood. De Billy Wilder, por ejemplo, se conoce la anécdota del sueño nocturno de una escena de apertura extraordinaria. El director anota la escena entre sueños y cuando se despierta al día siguiente solo lee «boy meets girl». El problema es obvio: las posibilidades de crear situaciones cómicas son menores que el apetito del público de ver nuevas comedias, razón demás para estudiar bien el mecanismo calderoniano de las variaciones mínimas de obra en obra, como ha señalado Wolfram Aichinger en un artículo reciente?

Parece mentira, pero mucho no se ha dicho sobre el artificio cómico de Calderón. No es que obras como La dama duende no hayan despertado el interés por parte de la crítica. Mucho, algunos dirán demasiado, se ha dicho sobre supuestos aspectos trágicos en las comedias cómicas de

${ }^{8}$ Zeilinger, 2007. Es cierto que Martínez Muñoz, 1991, presenta una diferenciación ligeramente diferente, pero para el propósito de este artículo nos basta con lo que se ha explicado.

${ }^{9}$ Aichinger (en prensa). 
Calderón ${ }^{10}$, corriente crítica que dice más sobre sus propias convenciones genéricas que sobre las obras de Calderón. Fue entre otros la labor de Luis Iglesias Feijoo e Ignacio Arellano demostrar que estas obras son en primer lugar comedias cómicas ${ }^{11}$.

En este artículo me gustaría presentar algunas observaciones acerca de estas obras que efectivamente son piezas cómicas. Sin embargo, no parece que deberíamos tratarlas como obras banales que solo servirían para un entretenimiento pasajero y superficial. Me he basado principalmente en Peor está que estaba, aunque comprobaré algunos de los resultados obtenidos para el caso de Mejor está que estaba. Es curioso que estas dos obras tan parecidas, casi se podría decir que de contrapunto, hayan tenido una suerte editorial muy diferente. Ambas obras datan de los prodigiosos años treinta; sin embargo, Peor está que estaba se incluye ya en la Primera parte de 1636, mientras que Mejor está que estaba solo llega a publicarse en 1683, en la Sexta parte confeccionada porVera Tassis, después de la muerte de Calderón.

Estas obras han sido estudiadas anteriormente por Sebastian Neumeister quien subraya en ellas la importancia del azar ${ }^{12}$. A pesar de que no estoy de acuerdo con todos sus resultados, en parte he podido basarme en sus trabajos. Sin embargo espero haber podido dar un paso más hacia la abstracción para hacer mis resultados útiles para la lectura de otras obras parecidas.

A continuación quiero describir cómo Calderón genera los típicos ingredientes que casi todas las contribuciones sobre el artificio cómico de Calderón destacan: el enredo, las peripecias, los lances y disfraces, y las simulaciones. ¿Cuáles son las herramientas para crear los efectos de la dialéctica entre «inevitability and surprise» descrita por Henry Sullivan ${ }^{313}$ Ya que su teatro es sobre todo un teatro de palabras tenemos que preguntarnos: ¿Cómo funciona la lógica comunicativa de sus obras?

${ }^{10}$ Ver sobre todo, Wardropper, 1966 o Leavitt, 1950. Existen muchos más trabajos de esta vertiente crítica. Para más ejemplos puede verse los artículos de Arellano, 1988 y 1990, e Iglesias Feijoo, 1998, que los recogen en gran medida.

${ }^{11}$ Arellano, 1988 y 1990; Iglesias Feijoo, 1998.

12 Neumeister, 1988, p. 143; 1989, p. 335.

${ }^{13}$ Sullivan, 1989, p. 125. 


\subsection{Referencias polivalentes}

Retomemos el hilo de la anécdota de «boy meets girl». Calderón utiliza la primera jornada para introducir a la mayoría de los personajes de la obra. Es la tarea que desde la Antigüedad griega nuestra cultura teatral le ha dado a la exposición. Pero en Calderón no solo se presenta a las dramatis personae, generalmente también suele presentar casi un segundo elenco de personajes. Me refiero al gran número de referencias a «un hombre bizarro», «una hija mía», «un caballero», o «una bizarra mujer» por solo citar los ejemplos de Peor está que estaba.Veamos un ejemplo en su contexto, escogido de la primera jornada de Peor está que estaba:

NISE

Una bizarra mujer, forastera al parecer, dice que te quiere hablar, si das licencia.

LISARDA

$¿$ No dice

quién es?

NISE

Solo dice que es una mujer.

LISARDA

Entre, pues ${ }^{14}$.

Sobra decir que la forastera que sale no revela su nombre, es más, dice que se llama Laura, cuando en realidad se llama Flérida.Volveremos sobre este recurso más abajo. Tratemos ahora de precisar este recurso del segundo elenco no identificado.

Claro está, este segundo elenco de personajes conformado por hombres y mujeres sin especificar, con el tiempo, a más tardar en la tercera jornada, se identificará con los personajes nombrados de la obra, no sin antes pasar por varias identificaciones equívocas. Calderón introduce en Peor está que estaba, y en muchas otras de sus obras cómicas, una serie de referencias polivalentes («una mujer», «un hombre», «un forastero»), como si tuviera una serie de comodines de un juego de naipes en la mesa y le tocará asignarlos a sus respectivos damas y caballeros ${ }^{15}$.

${ }^{14}$ Calderón, Peor está que estaba, p. 870 (la cursiva es mía).

15 Sobre relaciones entre el mundo del juego y el del teatro en la España áurea puede verse Nitsch, 2000. 
Estas referencias polivalentes son su herramienta básica para crear los famosos equívocos, lances y peripecias. La exposición en la primera jornada ofrece todo un abanico de estas referencias polivalentes y Calderón juega con las expectativas del público para la aclaración de estas referencias polivalentes, pasando muchas veces por varias identificaciones equívocas. Neumeister describe muy bien esta complicación de las identificaciones equívocas en Peor está que estaba que obligará a una dama incluso a actuar de sí misma pidiendo celos al galán cuando en realidad ella iba a encontrarse embozada con otro hombre ${ }^{16}$.

Parte de la fascinación de sus tramas radica en las hipótesis que el público se estará haciendo acerca de las identificaciones de estas referencias polivalentes. ¿Quién será esta mujer bizarra? ¿quién aquel hijo del que habla el personaje? ¿quién este hombre forastero vestido de secretario? ¿cuándo se enterarán los personajes de que quién es quién?

\subsection{Identificaciones equívocas}

Veamos ahora otro recurso muy frecuente en estas obras de Calderón. Y vamos a observar la lógica comunicativa ahora más bien del lado de los receptores. Mientras que la presentación de las referencias polivalentes es tarea de emisores, pasamos ahora a los receptores de estos mensajes llenos de posibles malentendidos. El segundo recurso comunicativo es el de las identificaciones equívocas. Cada lector de obras calderonianas las conocerá. Un personaje, digamos un padre, habla sobre una mujer que por una historia de amor pone en peligro su honra. El padre menciona este caso porque le acaba de llegar una carta en la que un amigo le pide ayuda al respecto. Su hija es a quién le habla sobre dicho caso usando las referencias polivalentes que acabamos de presentar. Debido a estas la hija piensa que la expresión «una mujer» se refiere a ella porque azarosamente tiene un secreto amoroso muy parecido. Escuchemos un ejemplo de Peor está que estaba. Habla Lisarda con su padre:

LISARDA

Parece

que estás triste.

GOBERNADOR

No te espante

ver en mí tan loco estremo,

${ }^{16}$ Neumeister, 1988, pp. 141-142. 
que, al fin, como padre temo.

¿Qué perdido caminante en noche obscura llegó donde a un pasajero viese robado, que no temiese? [...]

Yo, pues, en este papel, caminante, he descubierto dónde está el riesgo más cierto;

[...]

en él he visto la fiera

que darme la muerte espera, porque al fin es el honor, para quien su riesgo advierte, caza, camino y bajel, y están opuestos a él escollo, peligro y muerte. Vase.

LISARDA

Llena estoy de confusiones.

¿Si es que mi padre ha sabido

algo, Celia, y ha querido

con tan prudentes razones

avisarme de que tiene

peligro su honor? ${ }^{17}$

Las identificaciones equívocas son un punto de partida para la generalización del agente cómico descrito por Ignacio Arellano ${ }^{18}$, puesto que ellas son un recurso importante para la creación de galanes y damas ridículos, y para la estimulación del ingenio sobre todo de las damas. Lisarda será la que en Peor está que estaba tramará un lance tras otro y es curioso que siempre se basa en estas hipótesis falsas, fundamentadas en identificaciones equívocas. Este recurso aparece a lo largo de las tres jornadas. Calderón crea, pues, un mundo lleno de referencias polivalentes, lo que insta a los personajes a elaborar sus estrategias. Las estrategias de las distintas personas se cruzan y generan curiosas coincidencias azarosas, como destaca también Wolfram Aichinger ${ }^{19}$. Las referencias polivalentes y las identificaciones equívocas crean estos versos maravillosos en los que un personaje habla de tres mujeres que en realidad son una

${ }^{17}$ Calderón, Peor está que estaba, pp. 865-866.

${ }^{18}$ Arellano, 1994.

${ }^{19}$ Aichinger, en prensa. 
sola. Veamos el ejemplo de Mejor está que estaba. Aparece un tal Carlos que está de visita en la capital austriaca. Empieza a cortejar a una mujer embozada, por lo que se crea un duelo, luego se refugia en la casa de esta misma mujer y después de haber trasnochado en la cárcel donde Flora (la dama en cuestión) lo había escondido, esta misma se viste nuevamente de la primera dama para entregarle una joya. De manera que Carlos, que en principio no conoce a nadie en la capital imperial, dice cuando le anuncian la visita de la embozada:
¡Mujer a buscarme a mí!
¡Válgate Dios porViena, y cuáles son tus mujeres!
Apenas me he visto, apenas, en tu insigne corte, cuando una me llama y me arriesga, otra me ampara y me libra, otra me busca y me alienta $\mathrm{y}$ todas tres me ocasionan a que mil delirios tenga ${ }^{20}$.

Sobra decir que las tres mujeres que menciona son una sola. Otro aspecto que en este artículo no se podrá elaborar serían estas joyas, prendas, bandas y todo tipo de objetos que muchas veces suelen funcionar como identificadores, aunque a veces también se convierten en identificadores equívocos. De todas maneras, son una especie de contrapunto a las referencias polivalentes y un estudio de la dialéctica entre estas y los objetos identificadores sería muy interesante.

\subsection{Los juegos del azar}

Volvamos ahora a hablar del tema inicial de este trabajo: el azar o el acaso. El mundo de la comedia cómica de Calderón es un mundo de azares condensados. Se debe a una elevada cantidad de coincidencias azarosas, o fortuitas, que Lisarda de Peor está que estaba sea prendida en la casa de su amante por su propio padre, el gobernador, sin ser conocida por él. Este cree haber prendido a una dama fugitiva. Como los hombres presentes concuerdan en que será poco decoroso pedirle a la dama

\footnotetext{
${ }^{20}$ Calderón, Mejor está que estaba, p. 879.
} 
quitarse el velo, creen que, quien es en realidad la hija del gobernador, es otra dama diferente. Los hombres están además de acuerdo en que no debería encarcelarse a la mujer prendida, sino que estaría mejor en la casa del propio gobernador. Azarosamente ese mismo día la dama que el gobernador estaba buscando había llegado a la casa de Lisarda, es decir a la casa del gobernador, para pedirle auxilio, de manera que al llegar a casa no sospecha de su hija y está muy contento de haber preso lo que estaba buscando. La dama buscada curiosamente ni sabe que en principio está presa. Las referencias polivalentes o ambiguas y las identificaciones equívocas crean junto al azar la comedia.

Pero deberíamos tratar el azar desde dos perspectivas para comprender mejor la comedia calderoniana. Los personajes involucrados obviamente no pueden observar las causas de muchos de los azares presentes. En muchos casos los perciben como acasos objetivos, puesto que ignoran sus causas, por lo que apelan a la rueda de la fortuna, a Dios o a las estrellas.

El público, en cambio, sabe más, al menos lo suficiente como para darse cuenta de que todo se debe a azares epistémicos y disfrutan de observar a los personajes actuando en esa compleja red de referencias polivalentes, identificaciones equívocas y azares. Apunta Antonio Regalado:

Si la mentira, el equívoco y la restricción mental en juego con azares, conflictos, circunstancias y errores generan el enredo, el desenlace lo desata [...]. El arte de la comedia se complace en el caos, multiplicándolo para restaurar al final de la representación un orden pragmático y provisional matizado por la ironía $a^{21}$.

Wolfram Aichinger pregunta al respeto por qué estamos dispuestos a aceptar tantos azares ${ }^{22}$, que al fin y al cabo podrían parecer bastante incrédulos. Creo que una parte de la respuesta podría ser la comedia cómica misma. Los acasos basados en las referencias polivalentes e identificaciones equívocas provocan risa, y mientras que nos siga fascinando la obra los aceptaremos.

${ }^{21}$ Regalado, 1995, p. 449.

${ }^{22}$ Aichinger, en prensa. 


\section{Conclusiones}

Concluyendo se puede decir que todavía no entendemos bien lo que fue la comedia cómica del Siglo de Oro. Algunos tratan de convertirla en tragedia por un desprecio cultural hacia la comicidad, intentos que tienen que fallar. Otros tratan de valorarla por lo que es, una pieza cómica, pero opinan en cambio que serían mero entretenimiento autorreferencial.

La comedia cómica no es trágica como el juego no puede ser serio más allá de las fronteras del mismo. No obstante, los juegos solo pueden funcionar si los tomamos en serio. Así que quizá haya una tercera vía para entenderla. Son obras para reírse, eso sí, pero por eso no son menos interesantes y significativos como producto cultural que explora afectos y conceptos humanos básicos.

El Siglo de Oro español era un tiempo de una presencia muy marcada de juegos de naipes ${ }^{23}$. E incluso sin saber en detalle cuáles eran las reglas de estos juegos a cada lector se le hace evidente al instante la omnipresencia de la terminología de los juegos de cartas. La encontramos en Cervantes, Mateo Alemán, Lope, Tirso y, claro está, también en Calderón, y solo remito a los ya famosos artículos de Jean-Pierre Etienvre $^{24}$ y la muy recomendable contribución de Fernando Iwasaki Cauti, dedicada al juego de la polla en Cervantes ${ }^{25}$. Es decir, que el hombre y la mujer del Siglo de Oro estaban muy familiarizados con las estrategias de crear mundos hipotéticos para tratar de estimar las posibles ganancias o pérdidas que estaban en juego. Conocían la importancia de proyectar hipótesis cuantificadas hacia el futuro para tomar decisiones en el presente. No sorprende, pues, que precisamente en el siglo XVII aparecen testimonios importantes para el cálculo de probabilidades moderno. El historiador alemán Achim Landwehr describe como aparece en las matemáticas hacia la mitad del siglo XVII de donde pasaría poco a poco al conocimiento menos especializado ${ }^{26}$. El famoso intercambio epistolar entre Blaise Pascal y Pierre de Fermat trata precisamente del

${ }^{23}$ García García, 1999.

${ }^{24}$ Etienvre, 1984, 1985, 1989 y 1991.

${ }^{25}$ Ver Iwasaki, 2005, así como Scham, 2014.

${ }^{26}$ Landwehr, 2014, pp. 336-337. Es cierto que las anécdotas del tema y primeros cálculos se remontan incluso hasta la Antigüedad, pero es a partir del siglo XVII que podemos hablar de una debate continuo acerca del tema (Haller/Barth, 2014; Ineichen, 2002). 
problema de un juego de azar y lo que se proponen calcular no lo llaman todavía la "probabilidad», sino el azar. Cada jugador del Siglo de Oro trata de forzar de alguna manera el azar, algunos con trucos ilícitos, y es con ese trasfondo que Pascal y Fermat tratan de calcularlo ${ }^{27}$. Volvamos ahora a las comedias de Calderón. Si Borges nos hace vivir el infinito, Calderón nos brinda la posibilidad de experimentar los ambiguos juegos del azar. Calderón crea un teatro en el que experimentamos la contingencia, en el que se implica el espectador que formula hipótesis para aclarar las identidades de las referencias polivalentes, pero, y eso es importante, no se pierde las ocasiones para reírse de las identificaciones equívocas de los personajes, de sus estrategias fallidas y de los chistes de los graciosos, para admirar finalmente la habilidad del dios autor para el que nada de esto no es ni un azar epistémico ni uno objetivo, sino que forma parte del orden que ha creado.

${ }^{27}$ Mientras que en España intelectuales como Gracián tratan de descubrirlo. 


\section{BibLIOGRAFÍA}

Aichinger, Wolfram, "Casar imposibles. Las manos blancas no ofenden und das komische Artifizium Calderóns», Artificios, ed. Wolfram Nitsch, Paderborn, Wilhelm Fink, en prensa.

Arellano, Ignacio, "Convenciones y rasgos genéricos en la comedia de capa y espada», Cuadernos de Teatro Clásico, 1, 1988, pp. 27-49.

Arellano, Ignacio, «Metodología y recepción: lecturas trágicas de comedias cómicas del Siglo de Oro», Criticón, 50, 1990, pp. 7-21.

Arellano, Ignacio, «La generalización del agente cómico en la comedia de capa y espada», Criticón, 60, 1994, pp. 103-128.

Brême, Dominique, Georges de la Tour, Paris, Somogy Éditions d'art, 1997.

Calderón de la Barca, Pedro, Mejor está que estaba, en Comedias, VI. Sexta parte de comedias, ed. José María Viña Liste, Madrid, Biblioteca Castro, 2010, pp. 847-940.

Calderón de la Barca, Pedro, Peor está que estaba, en Comedias, I. Primera parte de comedias, ed. Luis Iglesias Feijoo, Madrid, Biblioteca Castro, 2006, pp. 859-952.

Étienvre, Jean-Pierre, "Naipes 'a lo divino' (textos literarios y folklóricos)", Revista de dialectología y tradiciones populares, 39, 1984, pp. 17-80.

Étienvre, Jean-Pierre, «El juego como lenguaje en la poesía de la Edad de Oro", Edad de Oro, 4, 1985, pp. 47-70.

ÉtIENVRE, Jean-Pierre, «La metáfora del juego y la vida política: de la imagen al modelo", Revista de Occidente, 102, 1989, pp. 87-96.

Étienvre, Jean-Pierre, «El juego entre rito y misterio», Revista de Occidente, 121, 1991, pp. 98-106.

García García, Bernardo, El ocio en la España del Siglo de Oro, Madrid, Akal, 1999.

Haller, Rudolf y Friedrich Barth, Berühmte Aufgaben der Stochastik. Von den Anfängen bis heute, München, de Gruyter Oldenbourg, 2014.

IgLesias Feijoo, Luis, "Que hay mujeres tramoyeras': 'La matemática perfecta' de la comedia calderoniana", en La comedia de enredo (XX Jornadas de teatro clásico de Almagro), ed. Felipe B. Pedraza Jiménez, Rafael González Cañal, Almagro, Ediciones de la Universidad de Castilla-La Mancha, 1998, pp. 201-236.

INEICHEN, Robert, «Würfel, Zufall und Wahrscheinlichkeit. Ein Blick auf die Vorgeschichte der Stochastik", Magdeburger Wissenschaftsjournal, 2, 2002, pp. 39-46.

Iwasaki Cauti, Fernando, «La polla de Cervantes. Consideraciones sobre cómo la remetería y qué pajillas echaría», Estudios públicos, 100, 2005, pp. 283-302.

Landwehr, Achim, Geburt der Gegenwart. Eine Geschichte der Zeit im 17. Jahrhundert, Frankfurt, Fischer, 2014. 
LEAvitT, Sturgis, "Did Calderón have a sense of humor?», en Romance studies presented to William Morton Dey, ed. Urban T. Holmes, Alfred G. Engstrom y Sturgis E. Leavitt, Chapel Hill, University of North Carolina, 1950, pp. 119-121.

Lem, Stanislaw, Philosophie des Zufalls. Zu einer empirischen Theorie der Literatur, Frankfurt, Insel Verlag, 1985.

Martínez Muñoz, Sergio, «El azar en la mecánica cuántica: de Bohr a Bell», Crítica: Revista Hispanoamericana de Filosofía, 23, 69, 1991, pp. 137-154.

Neumeister, Sebastian, "Pedro Calderón de la Barca. Peor está que estaba», en Das spanische Theater. Vom Mittelalter bis zur Gegenwart, ed. Volker Roloff, Harald Wentzlaff-Eggebert, Düsseldorf, Schwann Bagel, 1988, pp. 138-145.

Neumeister, Sebastian, «La comedia de capa y espada, una cárcel artificial: Peor está que estaba y Mejor está que estaba, de Calderón», en El mundo del teatro español en su Siglo de Oro: ensayos dedicados a John E. Varey, ed. José María Ruano de la Haza, Ottawa, Devehouse, 1989, pp. 327-338.

Nitsch, Wolfram, Barocktheater als Spielraum. Studien zu Lope de Vega und Tirso de Molina, Tübingen, Gunter Narr, 2000.

Nitsch, Wolfram, «El teatro barroco como juego. La villana de Vallecas, de Tirso de Molina», en Actas del V Congreso de la Asociación Internacional Siglo de Oro, ed. Christoph Strosetzki, Madrid / Frankfurt, Iberoamericana / Vervuert, 2001, pp. 934-940.

Regalado, Antonio, Calderón. Los orígenes de la modernidad en la España del Siglo de Oro, Barcelona, Destino, 1995.

Scham, Michael, Lector Ludens. The Representation of Games and Play in Cervantes, Toronto, University of Toronto Press, 2014.

Schütze, Sebastian, Caravaggio: das vollständige Werk, Köln, Taschen, 2009.

Sullivan, Henry W., «The Art of Fugue: Inevitability and Surprise in the Works of Calderón \& J. S. Bach», en Estudios sobre Calderón y el teatro de la Edad de Oro, ed. Francisco Mundi Pedret, Barcelona, Promociones y Publicaciones Universitarias, 1989, pp. 121-128.

Thuillier, Jacques, Georges de la Tour, trad. Bettina Blumenberg, Paris, Flammarion, 2003.

Wardropper, Bruce W., «Calderón's Comedy and his serious sense of life», en Hispanic Studies in Honor of Nicholson B.Adams, Chapel Hill, North Carolina, 1966, pp. 179-193.

Wussing, Hans, 6000 Jahre Mathematik. Eine kulturgeschichtliche Zeitreise 2. Von Euler bis zur Gegenwart, Berlin, Springer, 2009.

Zeilinger, Anton, «Der Zufall als Notwendigeit für eine offene Welt», en Der Zufall als Notwendigkeit, ed. Anton Zeilinger, Wien, Picus, 2007, pp. 19-24.

Zeilinger, Anton, «Zur Natur des Zufalls», en Kritik \& Utopie: Positionen und Perspektiven, ed. Hubert Christian Ehalt, Friedrich Achleitner, Konrad Paul Liessmann, Wien, LIT, 2009, pp. 447-450. 